\title{
Acute Paraplegia Due to Nucleus Herniation of a Mobi-C Implant without Trauma: Case Report of a Rare Complication
}

\author{
Sung Kyu Song, Jong-Myung Jung, Woo Kyung Kim, Sang Gu Lee, Yong Ahn, Seong Son, Byung Rhae Yoo \\ Department of Neurosurgery, Spine Center, Gachon University Gil Medical Center, Gachon University College of Medicine, \\ Incheon, Republic of Korea
}

Corresponding author:

Jong-Myung Jung

Department of Neurosurgery, Spine Center,

Gachon University Gil Medical Center,

Gachon University College of Medicine, 21,

Namdong-daero 774 beon-gil, Namdong-gu,

Incheon 21565, Republic of Korea

Tel: $+82-32-460-3304$

Fax: +82-32-460-3899

E-mail: jmjung2625@naver.com

Received: April 29, 2021

Revised: May 27, 2021

Accepted: May 31, 2021
Cervical artificial discs (CADs) are a surgical option in selected patients with cervical spinal disc degeneration. Although CADs have been available for many years, concerns persist regarding long-term safety, durability, and implant-related failure. We report a case of nucleus herniation of a Mobi-C implant without trauma, which is a rare complication. Two years after implantation of a Mobi-C implant, a 47-year-old man presented with acute paraplegia without a history of trauma. On cervical magnetic resonance imaging, a T2-high signal intensity lesion was noted in the ventral aspect of the spinal cord at the T1-2 level. During emergent surgery, nucleus herniation of the Mobi-C was detected. After surgery, the patient could walk without assistance. Posterior herniation of the Mobi-C nucleus without trauma is a rare complication that should be considered in surgical planning and follow-up.

Key Words: Arthroplasty; Cervical vertebrae; Intervertebral disc; Paraplegia

\section{INTRODUCTION}

Cenvical artificial discs (CADs) have been used as an alternative to anterior cervical discectomy and fusion (ACDF) to treat myelopathy and radiculopathy. Cenvical arthroplasty enables preservation or restoration of the natural disc motion of the treated level and acts as a spacer to maintain lordosis and foraminal height. Therefore, it can reduce pain, improve overall function, and decrease the risk of adjacent-level degenerative disease ${ }^{1-3,6,8,19-21)}$.

Outcomes following CAD treatment and ACDF have been compared in several prior studies ${ }^{13,18,26,27)}$. However, inconsistencies in adverse event reporting related to CADs have limited the interpre- tation of the clinical risks associated with the procedure ${ }^{23)}$. In this study, we report a patient who underwent emergency surgery for acute paraplegia due to nucleus herniation of a Mobi- $\mathrm{C}$ implant (polyethylene mobile implant) without trauma.

\section{CASE REPORT}

A 47-year-old man, who had previously undergone a C7-T1 arthroplasty with the insertion of a Mobi-C cenvical disc prosthesis for myelopathy 2 years ago at another institution, visited the emergency room with severe upper back pain and acute paraplegia. There was no history of spinal trauma, tumor, or infection preceding neurological deterioration. Dynamic cenvical X-rays and computed
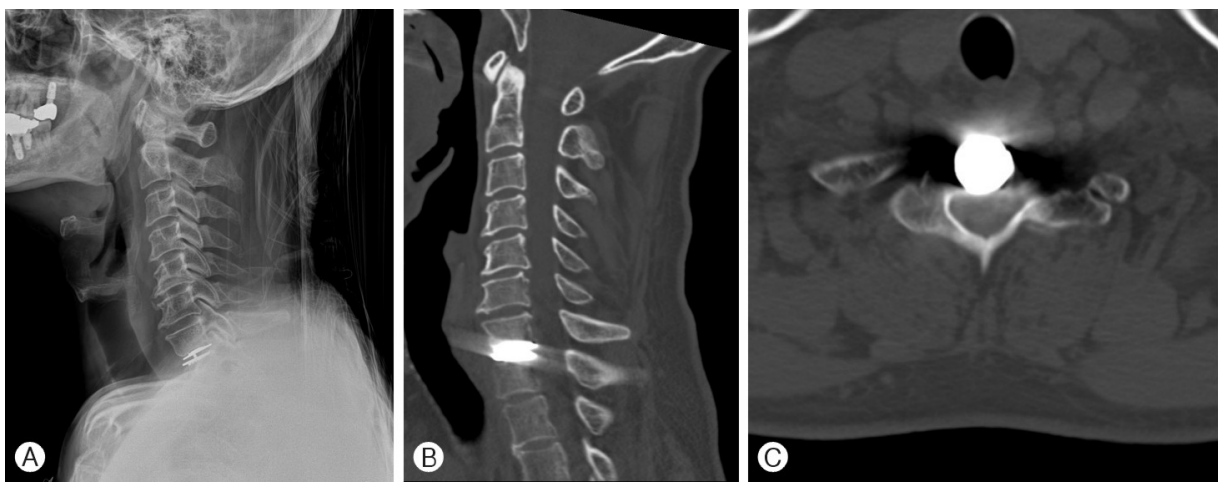

Fig. 1. (A) Preoperative cenvical X-ray and (B, C) computed tomography scans showed no abnormal findings. 
tomography (CT) scans showed no significant findings, but significant artifacts were present in the cervical region due to the previous cervical prosthesis (Fig. 1). Cervical magnetic resonance imaging showed a T2-high signal intensity lesion in the ventral aspect of the spinal cord at the T1-2 level (Fig. 2). It was not clear what the lesion represented. The CT myelogram was not considered due to the possibility of infection. Emergent surgical exploration was performed due to the acute onset of paraplegia.

After exposure of the vertebra, 14-mm Caspar pins were drilled into the $\mathrm{C} 7$ and $\mathrm{T} 1$ vertebral bodies for distraction. The plates of the prosthesis had subsided into the upper and lower vertebra, but removal of both plates was possible after drilling the junction. Posterior herniation of the nucleus was detected (Fig. 3). T1 corpectomy was performed to remove the nucleus of the prosthesis completely and safely. A titanium mesh cage filled with autologous bone was implanted and fixed using a ventral plate (Fig. 4). The patient underwent physical therapy and occupational therapy following his emergent operation. One month after surgery, the patient could walk without assistance.

The requirement for informed consent was waived due to the retrospective design and minimal risk of the study.

\section{DISCUSSION}

A multicenter prospective study with at least 10 years of follow-up was reported for one- and two-level cervical arthroplasty using Mobi- $C^{11)}$. At postoperative 10 years, patients maintained significant improvements in neck pain, arm pain, neck disability index, and segmental range of motion. No significant difference was found in the incidence of clinically relevant adjacent segment disease and motion-restricting heterotopic ossification between 7 years and 10 years postoperatively. CAD with a Mobi-C implant was concluded to be a favorable option as an effective surgical treatment for oneor two-level cervical disc degeneration.

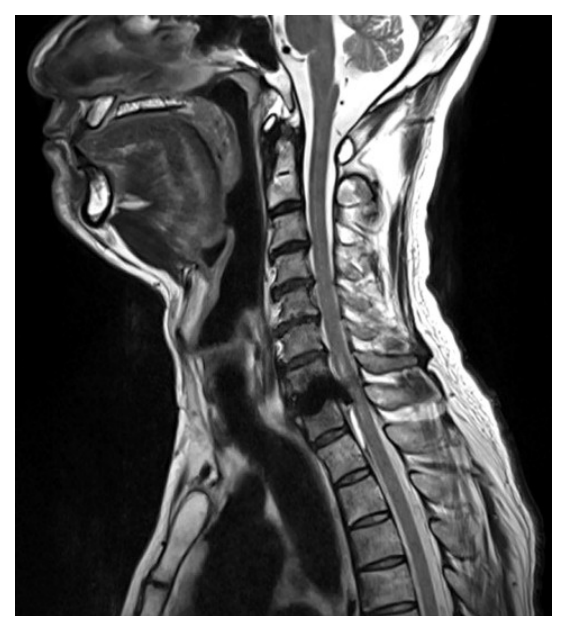

Fig. 2. Preoperative cervical magnetic resonance imaging showed a T2-weighted high signal intensity lesion in the ventral aspect of the spinal cord at the T1-2 level.
However, due to the limited reporting of adverse events related to $C A D s$, careful interpretation of the clinical risk is required ${ }^{23)}$. In randomized controlled trials of CAD treatment, the incidence of adverse events was very heterogeneous and showed significant variation ${ }^{15)}$. The reported modes of device failure include disc loosening, device or core migration, cracking of the implant sheath, and postoperative kyphosis, ${ }^{5,10,16}$. A previous study reported four patients who developed segmental kyphosis at the implant level after treatment with Mobi- $C^{7}$. The authors considered chronic device failure to be a cause of delayed segmental kyphosis. Inadvertent locking of the Mobi-C in extreme flexion may contribute to mechanical
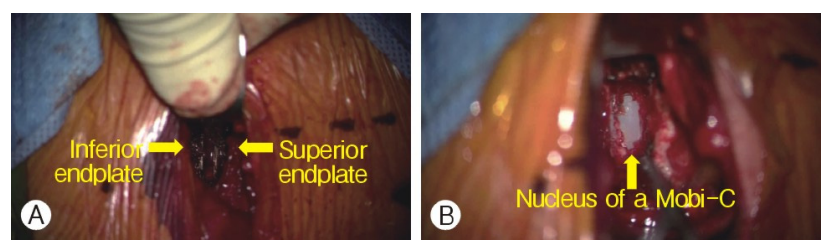

Fig. 3. Intraoperative images. (A) The superior and inferior endplates of the Mobi-C implant without a nucleus were observed. (B) After removal of both endplates of the Mobi-C, the nucleus of the implant was partially observed behind the $\mathrm{Tl}$ vertebral body.
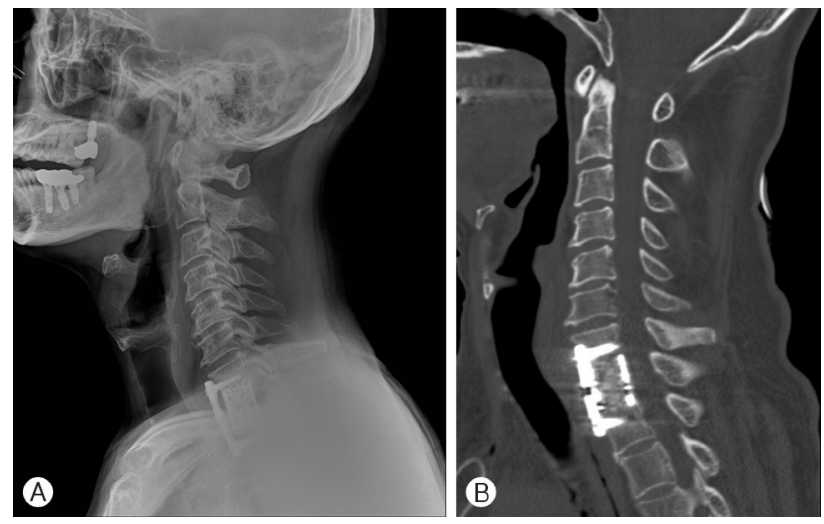

Fig. 4. Postoperative cenvical X-ray (A) and computed tomography scan (B) showed no unusual postoperative findings.

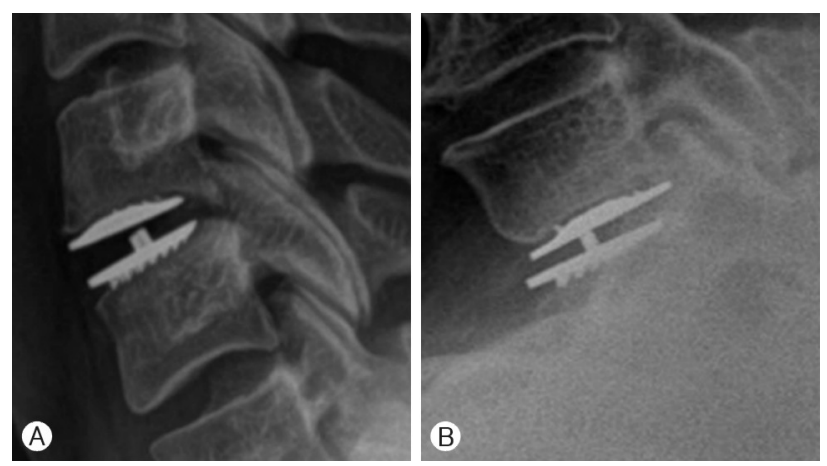

Fig. 5. (A) Normal cenvical X-ray after Mobi-C surgery. (B) In the preoperative cervical $X$-ray of the present case, the superior endplate of the Mobi- $C$ is located quite behind when compared to the lower endplate. This could be thought of as a clue to mechanical failure. 
Table 1. Reports of core herniation of Mobi-C in the literature

\begin{tabular}{|c|c|c|c|c|c|c|c|c|}
\hline No & References & Year & Age/Sex & Level & Preoperative symptoms & Reoperation & $\begin{array}{l}\text { Time between } \\
\text { surgery }\end{array}$ & Neurological improvement \\
\hline 1 & DiCesare et al..$^{7}$ & 2020 & $26 / M$ & C5-6 & Neck pain \& Lt. arm pain & C5-6 ACDF & 1 week & Resolution of all symptoms \\
\hline 2 & DiCesare et al. ${ }^{7}$ & 2020 & $48 / M$ & $\begin{array}{l}\mathrm{C} 5-6 \text { \& } \\
\mathrm{C} 6-7\end{array}$ & Neck \& bilateral arm pain & C5-6 \& C6-7 ACDF & 2.5 years & Resolution of all symptoms \\
\hline 3 & DiCesare et al. ${ }^{7}$ & 2020 & $60 / M$ & C4-5 & Neck pain \& arm pain & C4-5 ACDF & & \\
\hline 4 & DiCesare et al. ${ }^{7}$ & 2020 & $36 / M$ & C5-6 & Neck \& arm pain & Mobi-C disc replacement & & Resolution of all symptoms \\
\hline 5 & Pitsika and Nissen ${ }^{16}$ & 2020 & $44 / F$ & C6-7 & Gradually worsening myelopathy & C6, 7 corpectomy & 6 years & Resolution of all symptoms \\
\hline
\end{tabular}

M: male; F: female; Lt.: left; ACDF: anterior cervical discectomy and fusion.

failure. Furthermore, the mobile-bearing inside the Mobi-C flexes beyond the normal range of physiological motion ${ }^{22)}$.

In the present study, implant failure occurred 2 years postoperatively without physiologically abnormal conditions or trauma. In the preo- perative cenvical $X$-ray of the present case, the superior endplate of the Mobi-C is located quite behind compared to the lower endplate (Fig. 5). This could be thought of as a clue to mechanical failure. A possible cause of nucleus herniation is that the motion of Mobi- $\mathrm{C}$ may exceed the physiological range, while the structure of the implant is insufficient to limit it. The components of Mobi-C include superior and inferior cobalt chromium molybdenum alloy endplates coated with plasma-sprayed titanium and hydroxyapatite coating and a polyethylene mobile bearing insert. The interface between the inferior plate and the insert has two lateral stops to prevent excessive movement and migration of the nucleus. However, the inner surface of the superior plate lacks a similar feature. To our knowledge, herniation of Mobi-C is a very rare case with only 5 patients reported (Table 1) ${ }^{7,16)}$.

Artificial disc migration is more common on the ventral side" $12,14,17,24,25,28)$. However, acute paraplegia due to posterior herniation of the nucleus of a CAD without trauma is very rare ${ }^{4)}$. The imaging diagnosis was limited due to the presence of metal artifacts. The surgical treatment was also difficult because corpectomy should be performed to facilitate the removal of implants and adequate decompression of the spinal cord. This complication should be considered when counseling a patient about the surgical options for managing cenvical degenerative disc disease and during the followup period after $C A D$ surgery.

\section{CONCLUSION}

Implant failure of Mobi-C, especially nucleus herniation, may occur without trauma. Metal artifacts cause difficulty in the imaging diagnosis. This complication should be considered in surgical planning and follow-up.

\section{CONFLICTS OF INTEREST}

No potential conflict of interest relevant to this article was reported.

\section{REFERENCES}

1. Auerbach JD, Jones KJ, Fras CI, Balderston JR, Rushton SA,
Chin KR: The prevalence of indications and contraindications to cervical total disc replacement. Spine J 8:711-716, 2008

2. Badve SA, Kurra S, Nunley PD, Lavelle WF: The Mobi-C ${ }^{\circledR}$ cervical disc and other devices for two-level disc replacement: overview of its safety and efficacy. Expert Rev Med Devices 16:307-315, 2019

3. Beaurain J, Bernard P, Dufour T, Fuentes JM, Hovorka I, Huppert J, et al.: Intermediate clinical and radiological results of cervical TDR (Mobi-C) with up to 2 years of follow-up. Eur Spine J 18:841-850, 2009

4. Brenke C, Schmieder K, Barth M: Core herniation after implantation of a cervical artificial disc: Case report. Eur Spine J 24 Suppl 4:S536-S539, 2015

5. Cao JM, Zhang YZ, Shen Y, Ding WY: Complications of Bryan cervical disc replacement. Orthop Surg 2:86-93, 2010

6. Cason GW, Herkowitz HN: Cervical intervertebral disc replacement. J Bone Joint Surg Am 95:279-285, 2013

7. DiCesare JAT, Tucker AM, Say I, Patel K, Lanman TH, Coufal FJ, et al.: Mechanical failure of the Mobi-C implant for artificial cervical disc replacement: Report of 4 cases. J Neurosurg Spine: 1-7, 2020

8. Dooris AP, Goel VK, Grosland NM, Gilbertson LG, Wilder DG: Load-sharing between anterior and posterior elements in a lumbar motion segment implanted with an artificial disc. Spine (Phila Pa 1976) 26:E122-E129, 2001

9. Hacker FM, Babcock RM, Hacker RJ: Very late complications of cervical arthroplasty: results of 2 controlled randomized prospective studies from a single investigator site. Spine (Phila Pa 1976) 38:2223-2226, 2013

10. Johnson JP, Lauryssen C, Cambron HO, Pashman R, Regan JJ, Anand N, et al.: Sagittal alignment and the Bryan cervical artificial disc. Neurosurg Focus 17:E14, 2004

11. Kim K, Hoffman G, Bae H, Redmond A, Hisey M, Nunley $\mathrm{P}$, et al.: Ten-year outcomes of 1- and 2-level cervical disc arthroplasty from the Mobi-C investigational device exemption clinical trial. Neurosurgery 88:497-505, 2021

12. Lafuente J, Casey AT, Petzold A, Brew S: The Bryan cervical disc prosthesis as an alternative to arthrodesis in the treatment of cervical spondylosis: 46 consecutive cases. J Bone Joint Surg Br 87:508-512, 2005

13. McAfee PC, Reah C, Gilder K, Eisermann L, Cunningham B: A meta-analysis of comparative outcomes following cervical arthroplasty or anterior cervical fusion: results from 4 prospective multicenter randomized clinical trials and up to 1226 patients. Spine (Phila Pa 1976) 37:943-952, 2012 
14. Pickett GE, Sekhon LH, Sears WR, Duggal N: Complications with cervical arthroplasty. J Neurosurg Spine 4:98-105, 2006

15. Pitrou I, Boutron I, Ahmad N, Ravaud P: Reporting of safety results in published reports of randomized controlled trials. Arch Intern Med 169:1756-1761, 2009

16. Pitsika M, Nissen J: Spinal cord compression due to nucleus migration from Mobi-C total disc replacement. Br J Neurosurg [epub ahead of print, 2020. doi: 10.1080/02688697.2020. 1716942]

17. Quan GM, Vital JM, Hansen S, Pointillart V: Eight-year clinical and radiological follow-up of the Bryan cervical disc arthroplasty. Spine (Phila Pa 1976) 36:639-646, 2011

18. Ren C, Song Y, Xue Y, Yang X: Mid- to long-term outcomes after cervical disc arthroplasty compared with anterior discectomy and fusion: A systematic review and meta-analysis of randomized controlled trials. Eur Spine J 23:1115-1123, 2014

19. Riew KD: Editorial for effect of myelopathy on outcomes after cervical disc replacement: A study of a local patient cohort and a large national cohort. Neurospine 16:574-575, 2019

20. Samuel AM, Moore HG, Vaishnav AS, McAnany S, Albert T, Iyer S, et al.: Effect of myelopathy on early clinical improvement after cervical disc replacement: A study of a local patient cohort and a large national cohort. Neurospine 16:563-573, 2019
21. Sekhon LH: Cervical arthroplasty in the management of spondylotic myelopathy. J Spinal Disord Tech 16:307-313, 2003

22. Sekhon LH: Cervical arthroplasty in the management of spondylotic myelopathy: 18-month results. Neurosurg Focus 17: E8, 2004

23. Upadhyaya CD, Wu JC, Balamurali G, Haid RW, Traynelis VC, Tay B, et al.: Combined results of the 3 US IDE randomized cervical arthroplasty trials with 2-years of follow-up: 923. Neurosurgery 67:543, 2010

24. Wagner SC, Kang DG, Helgeson MD: Implant migration after Bryan cervical disc arthroplasty. Spine J 14:2513-2514, 2014

25. Wagner SC, Kang DG, Helgeson MD: Traumatic migration of the Bryan cervical disc arthroplasty. Global Spine J 6:e15e20, 2016

26. Wenger M, Markwalder TM: Bryan total disc arthroplasty: A replacement disc for cervical disc disease. Med Devices (Auckl) 3:11-24, 2010

27. Xing D, Ma XI, Ma JX, Wang J, Ma T, Chen Y: A metaanalysis of cervical arthroplasty compared to anterior cervical discectomy and fusion for single-level cervical disc disease. J Clin Neurosci 20:970-978, 2013

28. Zhang Z, Zhu W, Zhu L, Du Y: Midterm outcomes of total cervical total disc replacement with Bryan prosthesis. Eur J Orthop Surg Traumatol 24 Suppl 1:S275-S281, 2014 